\title{
ZeRow: Design, Energy Performance and Cost Analysis of a Solar Powered Row House
}

\author{
Roque T. Sanchez \\ B.A. Civil and Environmental Engineering, 2009 \\ M.S. Environmental Engineering Sciences, 2010 \\ Rice University \\ Houston, TX 77005 \\ roque.t.sanchez@alumni.rice.edu \\ Allison A. Elliott \\ B.A. Economics, 2010 \\ B.A. Hispanic Studies, 2010 \\ Rice University \\ Houston, TX 77005 \\ allison.a.elliott@alumni.rice.edu \\ Rebecca Sibley \\ Master's Candidate, Architecture \\ Rice University \\ Houston, TX 77005 \\ rmrsibley@rice.edu \\ Nonya S. Grenader \\ Professor in Practice \\ Associate Director, Rice Building Workshop \\ School of Architecture \\ Rice University \\ Houston, TX 77005 \\ nonya@rice.edu \\ Brent C. Houchens \\ Assistant Professor \\ Department of Mechanical Engineering and Materials Science \\ Rice University \\ Houston, TX 77005 \\ houchens@rice.edu \\ Danny M. Samuels \\ Professor in Practice \\ Director, Rice Building Workshop \\ School of Architecture \\ Rice University \\ Houston, TX 77005 \\ samu@rice.edu
}


Abstract - Architecture and engineering students designed and constructed an affordable, solar powered row house for implementation in a historically low-income area of Houston, Texas. This ZeRow House is tied to the electric grid for purchase of electricity at night, but compensates for this cost by generating more power than needed during the day when electric grid demands peak. The result is a home with net-zero energy purchased from the grid and the simultaneous elimination of battery storage. Electricity is supplied back to the grid during the peak daytime demand hours, a particularly significant contribution in the hot, humid summer months in Houston. This home was one of twenty entries in the 2009 Department of Energy's Solar Decathlon. Throughout the project, design decisions were always mindful of the final purpose: the demonstration of an affordable, easily reproducible solar-powered home that honors the row house tradition of Houston's Third Ward, while taking advantage of modern, durable materials and state-of-the-art energy conversion technology, and bringing a focus on sustainability and education to the greater community.

Index Terms - architecture, engineering, Project Row Houses, Solar Decathlon, ZeRow

\section{INTRODUCTION}

Distributed solar power generation is currently underutilized in the U.S., particularly in settings such as low-income housing where designs and construction must be cost effective. The problem of affordable sustainable housing is addressed here, with consideration for not only the climate and power generation requirements, but also the historical and cultural significance of the neighborhood. Furthermore, the desire to simultaneously increase public awareness of alternative energy systems is addressed. These concepts have driven the design, construction and implementation of the Zero Energy Row House (ZeRow House)

The U.S. Energy Information Administration predicts that adoption of renewable energy technology will continue to increase through $2030^{\mathrm{i}}$, driven by both increasing costs and environmental impact of traditional hydrocarbon electricity generation and heating. For example, retail cost of residential electricity in Texas nearly doubled from $7.2 \phi / \mathrm{kWh}$ to $13.04 \phi / \mathrm{kWh}$ over the last 20 years, as shown in Figure $1^{\text {ii }}$. Note that this period includes the deregulation of residential electricity in Texas in 2002. Distributed solar electricity generation and hot water heating represents an investment in energy price stabilization to the end user. The taxation of byproducts of hydrocarbon production and consumption, such as $\mathrm{CO}_{2}$ in the European Union Emissions Trading Scheme, will spur the adoption of solar energy generation free from greenhouse gas emissionsiii.

The project discussed here is the design and implementation of a sustainable, energy-efficient solar-powered home that is sufficiently affordable to serve as a prototype for low- and mixedincome housing projects. A thirteen year collaboration between Project Row Houses in Houston, Texas and the Rice Building Workshop at Rice University offered a perfect opportunity to attempt such an implementation. Coupled with a successful proposal to the Department of Energy's Solar Decathlon competition ${ }^{\text {iv }}$, the ZeRow House project was initiated with a goal of designing a grid-tied home that could generate all of the power needs of the occupants, yielding net-zero purchased electricity over the duration of a yearv . 


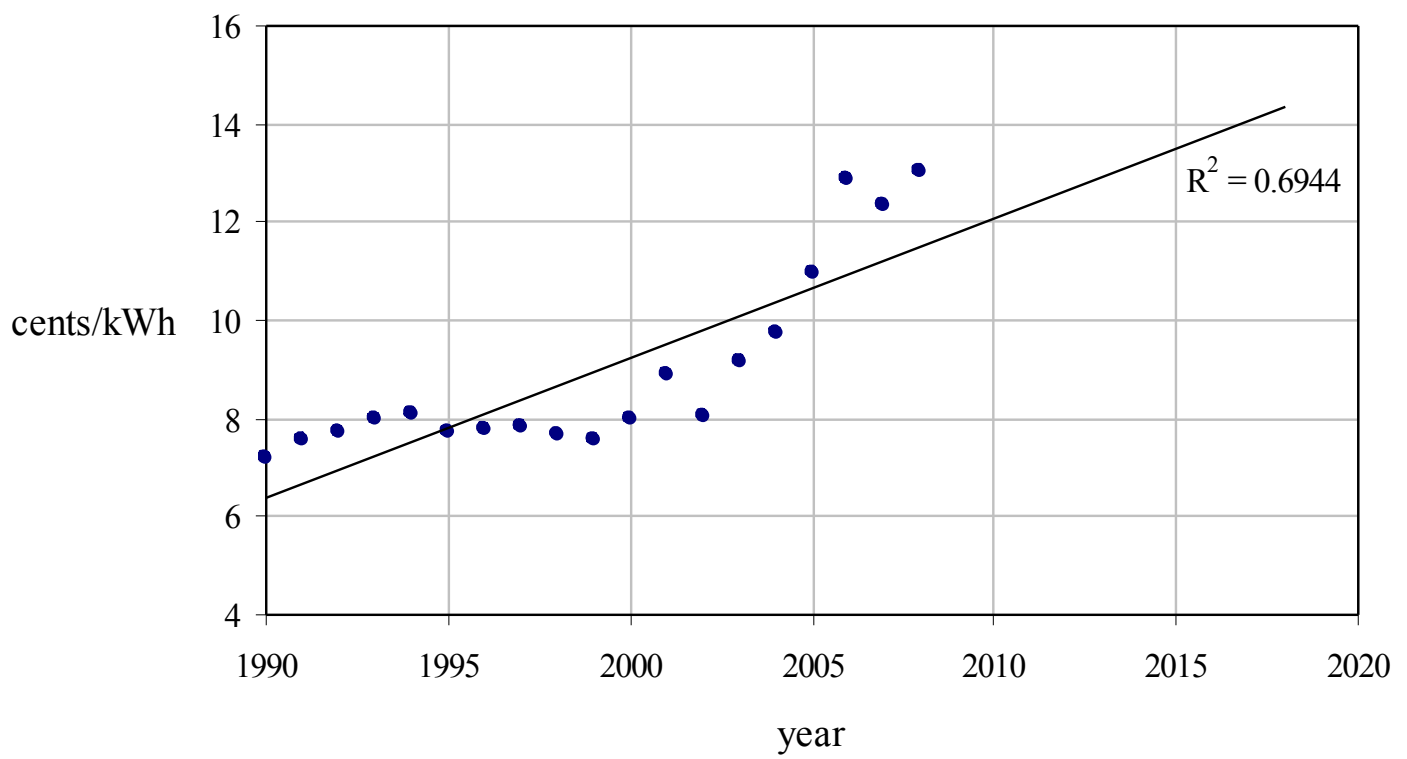

FIGURE 1

Retail cost of Residential electricity in TeXas, 1990 to 2008

\section{Solar Decathlon}

National laboratories, industrial manufacturers and universities are all expending considerable research efforts to improve the efficiencies of photovoltaic materials and devices. However, challenges facing the implementation and integration of residential solar energy conversion did not receive significant funding through the 1990s. This resulted in a gap between technology developers and end-user homeowners. The U.S. Department of Energy (DOE) took on the task of educating the public and bringing practical solutions to use by developing the Solar Decathlon competition in $2002^{\mathrm{v}}$.

University teams selected to compete in the Solar Decathlon design and build a solarpowered house. The houses are transported to Washington, D.C. and a solar village is constructed on the National Mall. The Solar Decathlon competitions held in 2002, 2005 and 2007 involved grid-independent homes with energy storage. In 2009 the focus switched to gridtied homes in which excess energy produced during the day is sold back to the grid and electricity is purchased at night when demands are typically lower. According to the National Renewable Energy Laboratory (NREL), which administers the Solar Decathlon, the competition is designed to "foster development and facilitate widespread adoption of solar-powered homes that demonstrate solar technologies in marketable applications, through technology development and key partnerships" with universities and their local partners ${ }^{\mathrm{vi}}$.

\section{Mixed-Income Community Development}

The ZeRow House was designed for eventual implementation at Project Row Houses (PRH) in Houston, Texas. PRH describes itself as "a neighborhood-based nonprofit art and cultural organization" in Houston's Third Ward ${ }^{\text {vii }}$. It was founded by a group of local artists to impact and reclaim the inner-city community in which they lived. Since its founding in 1993, the art, social, and educational programs initiated by PRH have in fact transformed the neighborhood. 
The physical campus consists of 29 reclaimed historic structures and 17 new structures covering six urban blocks. Of these, about a dozen reconstructed row houses are dedicated to revolving art installations, seven are used for the Young Mothers Program, and several are office, artist-inresidence, and workshop spaces. Sixteen structures built in the last few years include thirty apartments available for mixed-income rental, with income-based rental gradation. PRH is built on the principles of creating effective communities as described by artist Dr. John Biggers (1924 - 2001), namely "(1) art and creativity should be viewed as an integral part of life, exemplified in African traditions wherein art is interwoven into the very fabric of life through rituals and ceremony activities, (2) quality education is defined through impartation of knowledge and wisdom - including understanding that is passed from generation to generation, (3) strong neighborhoods have social safety nets, woven by community to support community and to raise social responsibility and (4) good and relevant architecture; meaning housing that should not only be well designed, but also make sense to preserve a community's historic character."

Since 1997, the Rice Building Workshop has collaborated with Project Row Houses to design, develop, and build a range of affordable house prototypes. The Rice Building Workshop (RBW), a part of the Rice School of Architecture, was formed in 1996 with the goal of bringing students out of the school and into the larger community, where their creativity could be challenged by the demands of real-life practice. Over thirteen years, more than 300 students of architecture, engineering, and other disciplines have engaged in these projects ${ }^{\text {viii. }}$.

\section{ObJectives}

In undertaking the design of the ZeRow House, the goal was to demonstrate an affordable, sustainable home as a prototype for low-income community-centered housing. This was implemented through RBW classes and engineering independent study courses. Focus was placed on finding the most promising and widely available technologies that would lead to the best return on investment or most cost-effective solutions, while ensuring that these technologies could be implemented in ways consistent with the architecture and community at PRH.

\section{Architecture Objectives}

The ZeRow House is an affordable, zero-energy home designed specifically for Houston, with a site in the heart of the city at Project Row Houses, in Houston's Third Ward. The row houses typical to Houston's Third Ward are high-density urban housing derived from traditional African and Caribbean house types that migrated across the Southern United States ${ }^{\mathrm{ix}}$. Also called shotgun houses, where rooms lead directly into one another in a line, these modest houses are placed nearby each other, and are lined up in rows for blocks. Row houses have a recognized form that resonates with the historic significance and culture of the Third Ward. The design of the ZeRow House is based on respecting the character of the existing homes and the community, and reimagining the row house typology in terms of an affordable solar house for Houston that can produce on-site its yearly energy needs for operation.

The ZeRow House, like its row house antecedents, is a small, functional home that contains all that is needed for everyday living with great efficiency. At 520 square feet of conditioned space, each area was carefully designed to meet the needs of the future occupants at Project Row Houses. Possible occupants for the ZeRow include single adults or retired couples, single mothers with infants, or artists-in-residence. The house is conceived and constructed using conventional building systems that are low-cost, readily available, and familiar. The result is intended to be cost-effective, durable, and easily replicated ${ }^{\mathrm{x}, \mathrm{xi}}$. 


\section{Engineering Objectives}

The engineering goals were straightforward: utilize robust technology to design just to the energy needs of the ZeRow House. In choosing to be efficient, the team realized that the bonus points for excess generation award in the Solar Decathlon would be sacrificed. These points have typically played a large role in the outcome of the competition. Nonetheless, the ZeRow team felt that designing the most economically viable home could have the greatest impact on the target community.

\section{Solar Decathlon Objectives}

The 2009 DOE Solar Decathlon, the fourth Solar Decathlon event sponsored by the DOE, was the first Decathlon to feature grid-tie technology. While all previous Decathlons featured electricity grid-independent prototype houses, the National Renewable Energy Laboratory (NREL), also a sponsoring organizer of the Decathlon, determined that grid-tie systems were a more viable market and thus more deserving of research focus.

Following prototype setup on the National Mall, research teams participate in eight days of performance competition. Prototypes are judged in ten contests-the namesake decathlon-five of which are subjective contests and five of which are objective. The subjective contest categories are architecture, market viability, engineering, lighting design, and communications, and are judged by a jury of professionals in the given fields. These juried categories are designed to gauge how the house prototypes will function in their target markets. The objective tests measure the physical performance of the house as determined from measurements made from sensors installed by NREL. The objective contests are comfort zone (interior temperature and humidity), hot water production, appliance performance, home entertainment, and net metering. The home entertainment contest includes two subjective sub-categories, dining and home theater, which are judged by peer competitors.

Among the ten contests, 1000 points are available to each team and the team with the highest score wins the Decathlon. All contests except net metering are assessments of the prototypes independent of all other prototypes; houses are awarded points based on a rubric or metric and one house's score does not affect the scores of other houses. The net metering competition has 100 points available if the prototype achieves net-zero energy consumption, and a portion of full points are awarded for teams with net-positive energy consumption. The team that produces the most excess electricity for export receives the full 100 points and also receives an additional 50 bonus points. Other teams who are net electricity exporters receive a fraction of the 50 bonus points based on ranking.

\section{Long-Term Objectives}

Since the implementation of the ZeRow House, the long-term goal is to educate the PRH community about sustainable lifestyles. Residents of the ZeRow House will be able to adjust their energy use and directly observe reductions in electricity bills. A frugal electricity consumer could even sell a net amount of electricity back to the grid and be paid to do so.

\section{Architectural Design}

The ZeRow House offers a unique zero-energy home that places an emphasis on both solar power and affordability. In demonstrating the viability of photovoltaics and solar hot water for a mixed-income market, the team further supports the notion that zero-energy housing is a practical goal for an average American homeowner. Interest in solar technologies continues to 
increase with increasing energy costs, but the reality of owning solar energy collection systems seems out of reach for much of the public due to concerns with the high upfront costs, accessibility, and perceived maintenance issues. Additionally, homeownership and the costs associated with it have been pushed to the national stage with recent economic struggles. The ZeRow House meets the demands of a shifting market and economy, where documented interest in solar energy and good design does not have to be sacrificed for cost, but instead becomes both affordable and accessible to a much larger audience. The cost of reproducing the ZeRow House is $\$ 125,000$, which consists of $\$ 100,000$ in traditional construction costs and $\$ 25,000$ in alternative energy technical systems (solar arrays, micro-inverters and solar hot water system).

\section{Concept}

The ZeRow House is organized around two cores, as shown in Figure 2, which serve as the basis for the modernization of the traditional row house: the wet core and the light core. The wet core contains all systems associated with water. The light core serves as the primary source for daylighting and as an extension of the living space. Although the idea of packaging all the technical support functions in a single element has been proposed numerous times ${ }^{\text {xii,xiii,xiv }}$, contrasting it with the dissimilar light core is a novel architectural concept.

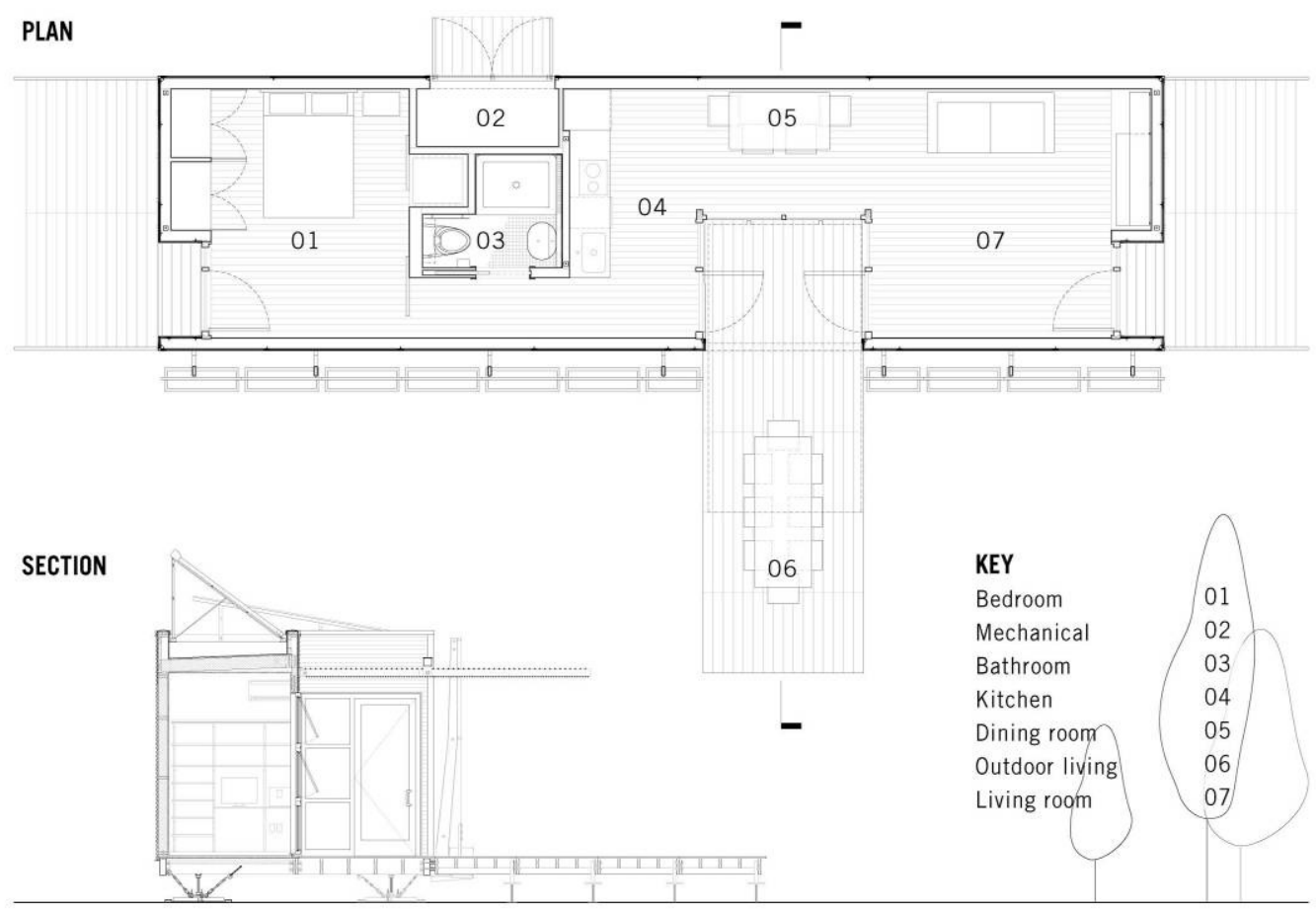

FIGURE 2

Floor Plan of the ZeRow House

Public and private zones are created by the diametric placement of the cores in the rectangular row house footprint. The result is a re-interpretation of a Houston row house: instead of the traditional linear sequence through the house, spaces flow dynamically to one another and to the exterior. The evolution of the shotgun-style to the final ZeRow House is depicted in Figure 3. 


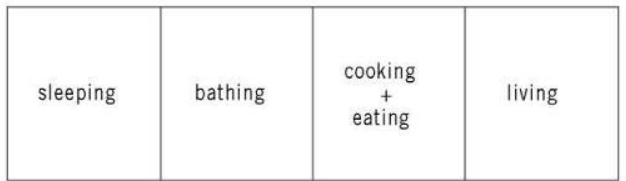

Typical Program

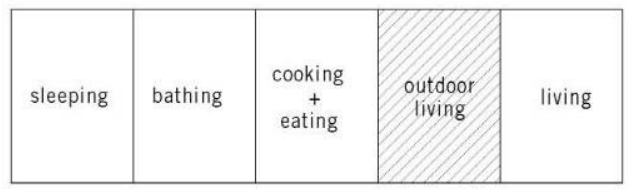

Program Augmented

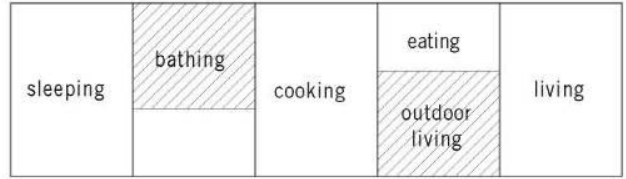

Program Reogranized

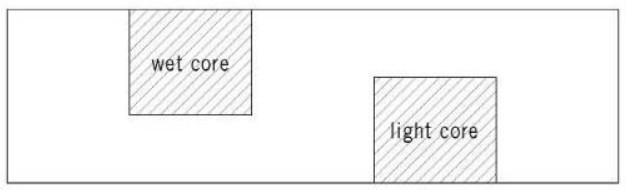

Two Cores

FIGURE 3

Evolution FROM THE TRADITION SHOTGUN-STYLE ROW HOUSE TO THE TWO-CORE ZERow House

\section{Envelope and Structure}

Previous houses that Rice Building Workshop built at Project Row Houses were intentionally and strongly influenced by the specific architecture of the old row houses due to their location in and near the historic area and utilized pitched metal roofs, front porches, board siding, doublehung windows, and other features common to row houses. However, as the ZeRow House was to be located on the periphery of the campus, the ZeRow House team determined in early discussions with the PRH staff and stakeholders that the contextual constraints could be somewhat relaxed, and that the row house type could be re-interpreted in a more fundamental way. Furthermore, the size and shape of the ZeRow house was constrained by considerations of 
portability: the basic size of the house was the largest unitary load that could be placed on a drop-bed extendable trailer and driven from Houston to Washington, D.C. and back with the minimum of special permitting. This limited the size to $14^{\prime}$ wide $\mathrm{x} 12^{\prime}$ high $\mathrm{x} 50^{\prime}$ long, which is the same footprint as a typical row house. However, with the height limitation, the design team opted for a flat roof instead of the traditional 7:12 pitched roof.

A rigid steel chassis is the structural backbone for the house, distributing loads to six foundation piers that correspond to crane lift points. Each foundation pier can be screw-adjusted to accommodate varying topography. The structure above the chassis is a conventional wood frame. Walls are 2"x6" construction, stiffened by plywood diaphragms glued and screwed in each plane. Three shear walls, one at each end and one separating the kitchen and bathroom, provide lateral stiffness. Floor and roof are framed with 2"x10" lumber. Decks, stairs, ramp, green wall, and sunshade are designed to be transported separately and quickly attached.

Many of the structural decisions were influenced by the problem of transportation to the National Mall for competition purposes. If the ZeRow House were to be built onsite at Project Row Houses, the floor joists would be constructed entirely out of wood members, eliminating the need for contracted fabrication of the chassis, and the shear wall requirements would be reduced, lowering the cost of construction and materials.

\section{Exterior Materials}

Exterior materials were selected for durability and minimal maintenance. Durable materials were necessary not only for the wear and tear during 3,000 miles of transportation, but also to minimize life-cycle cost and maintenance expense in long-term usage, an advantage seldom seen in low-cost housing. The walls are covered in 22 gauge corrugated steel, coated with Galvalume ${ }^{\circledR}$ finish, a very strong and durable exterior finish of 55\% Aluminum-Zinc shown in Figure 4. While significantly different in composition from the traditional board siding used in the original row houses, the Galvalume ${ }^{\circledR}$ is oriented horizontally to maintain the long shotgunstyle. This is the modern materials embodiment of the traditional style, which minimizes maintenance. The roof membrane is TPO (thermoplastic elastomer), a single-ply welded material with a white reflective surface. Windows and doors are anodized aluminum with 1" Solarban 60 low-emissivity insulated glass. Floor, wall, and roof assemblies are insulated with Icynene ${ }^{\circledR}$ closed-cell expanded foam to minimize thermal losses. 


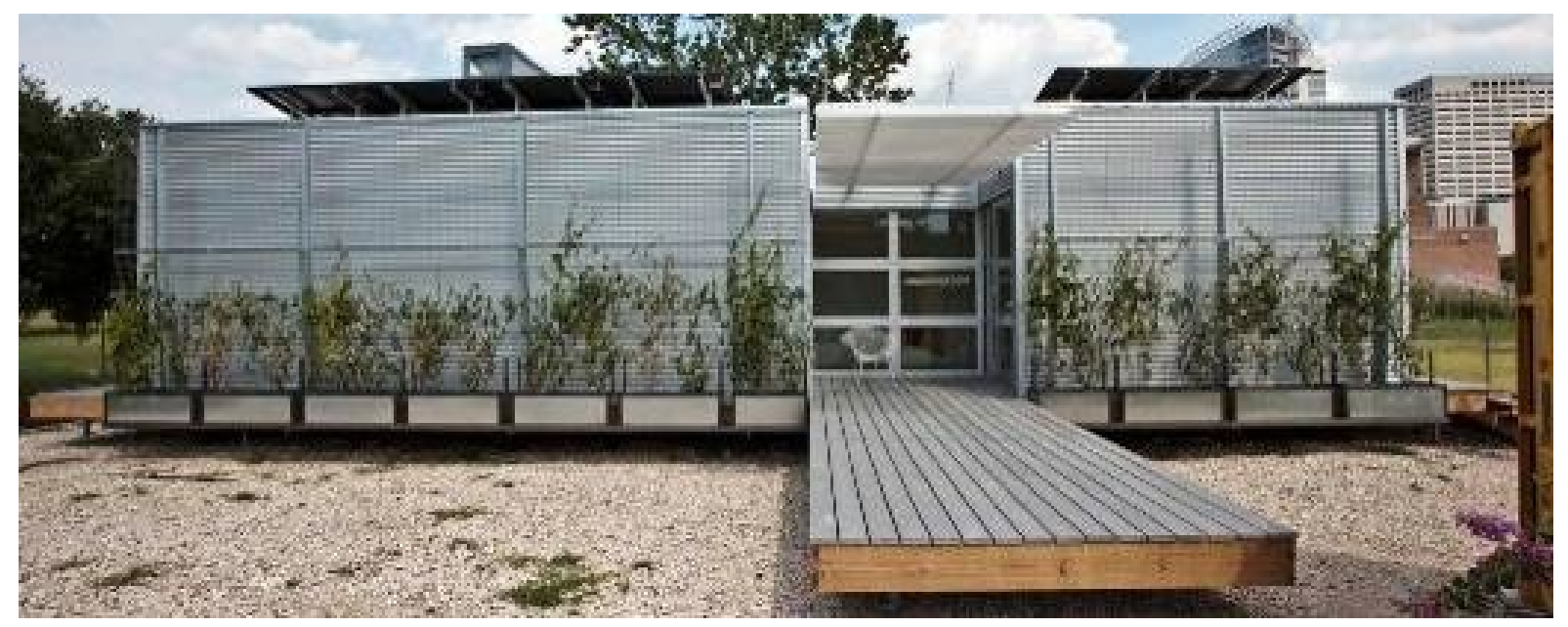

FIGURE 4

ZeRow House at Rice, just before shiping to Washington, DC (photo by Eric Hester C)

\section{Green Wall}

When fully mature, the green wall will add shade to the most exposed surface of the ZeRow House, providing passive solar cooling. The plants will essentially form a double skin along the building, absorbing the radiant heat of the sun on their surface, while allowing air to circulate in the space between the plants and the house.

A mix of native and local plants fill out the green wall. Each plant is non-invasive and requires low to no watering once fully established. The three species are Tangerine Crossvine, Coral Honeysuckle, and Star Jasmine. The plants were not only selected for their water sipping qualities, but also for their beautiful, fragrant red and white flowers that bloom in the spring and attract butterflies. Each vine is either fully or partially evergreen, so the green wall will remain green and functional, even in the short Texas winter.

The design of the green wall had to address local resources, budget, hurricane winds and transportation. The screens and boxes are supported by seven custom fabricated steel fins that attach to the ZeRow House chassis, so as to not interfere with the continuous metal skin of the home. All components of the wall structure are galvanized, to ensure their weather resistance.

\section{Cores}

The light core is an outdoor extension of the interior living space, covered with an exterior sunshade structure. Aluminum doors and operable windows provide access, natural ventilation, and daylight. 

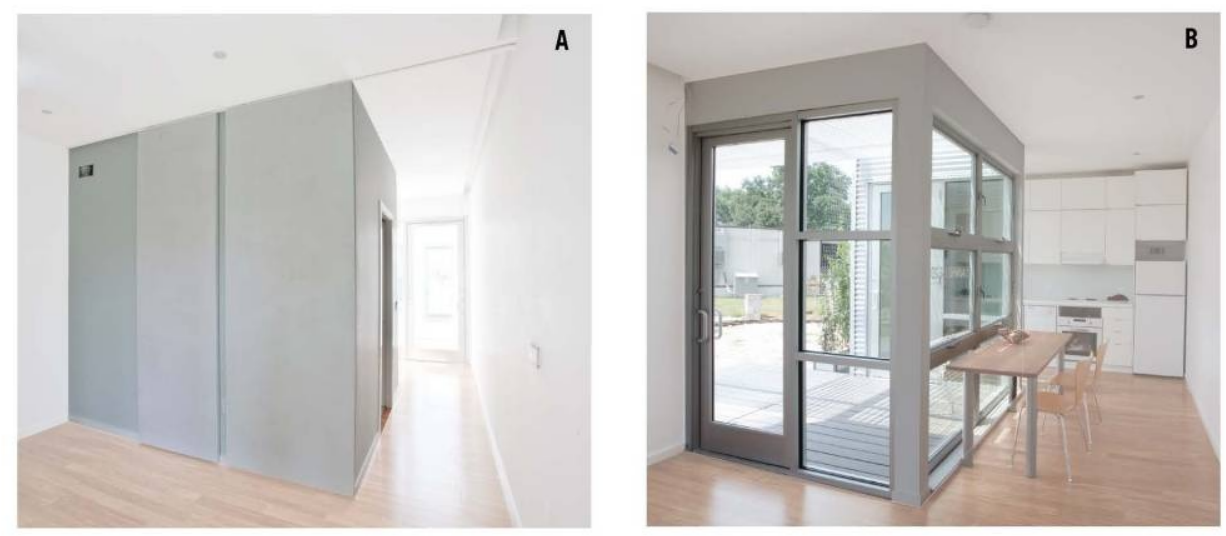

A Wet Core

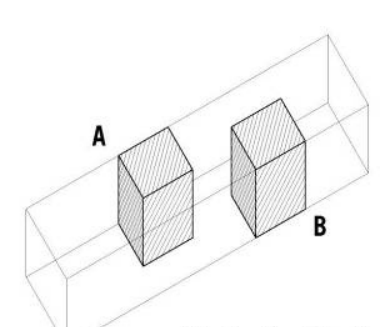

B Light Core

FIGURE 5

THE WET CORE AND LIGHT CORE AS VIEWED FROM THE BEDROOM AND LIVING ROOM, RESPECTIVELY (PHOTOS BY ERIC Hester (C)

The wet core packages all of the main mechanical, electrical, and plumbing components of the ZeRow House into one central unit. This 8'-0" by 10'-0" space in the house bundles the kitchen, bathroom, washer and dryer, electrical, plumbing, HVAC, and solar systems. Designed with a potential for prefabrication in mind, the wet core holds promise for building more costefficient houses in the future by allowing contractors to bring in the self-contained, preassembled unit and build the comparatively inexpensive house frame around it.

\section{Interior Design}

All interior spaces are defined and enhanced by the placement of the cores. Living, dining, and kitchen areas share the amenities of the light core with its natural ventilation and extension of living space. Nine foot ceilings offer a more generous interior volume, sustainable bamboo wood floors (durable and fast-growing) unify the interior spaces, and low VOC paint is used throughout.

The kitchen is a unitized culinary work space that maximizes the amount of storage available along the length of the wet core. Affordable IKEA millwork runs to the ceiling, and the careful placement of kitchen appliances allows for maximum space and efficiency in a small kitchen area. The key features are smaller, Energy Star rated appliances, which result in lower energy use; low flow faucets (1.75 gallons per minute) that are a $30 \%$ reduction from normal water use; and affordable off-the-shelf products. 
The living room houses a flexible shelving system designed with ELFA hardware and student built medium-density fiberboard (MDF) shelving that functions as a combined workspace, entertainment area, and storage space.

The placement of the wet core (kitchen, bath, laundry and mechanical) divides the public areas from the more private bedroom. The bathroom is packaged into the wet core and features only water saving fixtures: a dual flush toilet (0.8 / 1.6 gallons per flush) and a low-flow faucet. One wall of the bedroom features a pair of sliding doors that provide privacy and conceal the stacked Energy Star washer and dryer. The opposite bedroom wall is lined with a flexible IKEA wardrobe that maximizes storage, though previously owned or refurbished furniture could be substituted.

An accessible route is provided according to Fair Housing standards. A gentle ramp runs the length of the house, ascending to the back porch. Doors and thresholds comply with wheelchair access standards. Although the kitchen and bathroom do not incorporate every feature of accessibility, it would be a simple matter to modify them to do so.

\section{Lighting}

Passive daylighting is instrumental to the basic design of the house. The light core provides daylight into the more public portion of the house, filtered by the sunshade. Glass doors and sidelights provide daylight and ventilation at the end walls. In general, the strategic placement and limited use of glazing reduces glare and heat gain from Houston summers.

LED lights were used throughout the entire interior and exterior of the ZeRow House. Recessed down-lights with 1 or 3 watt lamps distributed throughout the living, sleeping, and bathroom areas provide an even distribution of light. A light cove fitted with a dimmable LED strip runs the length of the house and provides indirect light washing along the wall, as well as supplemental light on cloudy days. LED task lighting is provided at the desk. Recessed strip lighting is built into the kitchen cabinetry for task lighting at the countertop. The total wattage for all the interior luminaries and their drivers is less than 200 watts.

\section{Engineering Design}

The ZeRow House is designed to produce enough energy through solar technology for the house to run independently during the day, while producing sufficient excess electricity to sell to the grid during peak hours. Through solar panels and a solar hot water system, the house is supplied with energy to run the HVAC, appliances, and lighting while supplying hot water for the bathroom, kitchen and laundry needs. In the evenings, electricity is purchased back from the grid at off-peak pricing. Between purchasing from and selling back to the grid, the net electricity demand is zero. There are no batteries, reducing maintenance and improving the long-term sustainability. The wall and window construction reduce the amount of heat gained or lost. LED lighting, Energy Star rated appliances, and an efficient HVAC mini-split system all minimize energy usage.

The ZeRow House has off-the-shelf solar photovoltaic panels that a typical homeowner could purchase. An appropriately-sized array of 24 panels was designed, producing $4.2 \mathrm{~kW}$, for the 520 square foot house. Angling the solar array at $15^{\circ}$ allows the panels to be exposed to the maximum amount of sunlight during the year.

\section{Photovoltaic System}

The ZeRow House uses 24 BP175B solar modules. This 175 W DC module, manufactured by 
BP Solar USA, has been widely distributed internationally and was chosen to balance cost, longevity, and energy production.

A micro-inverter system by Enphase Energy allows conversion to AC electricity at each panel. This introduces redundancy in the system. Furthermore, unlike traditional systems with one large inverter, micro-inverter technology has four other advantages. First, each panel reports its generation to a central data logger. This allows for quick troubleshooting of underperforming panels. Second, this system eliminates the high voltages generated in traditional series connected DC arrays, which require specially licensed electricians for installation and repair. Third, the panels become plug-and-play, allowing homeowners to add panels as they can, without designing for the final total array. Finally and most importantly, inverting at each panel reduces the negative impact of partial shading. In traditional systems connected in series to increase the DC voltage, the poorest producing panel brings down the performance of every other panel, each of which must match the low current production of the shaded or damaged panel. With microinversion, panels in full sunlight do not suffer from shaded or damaged panels.

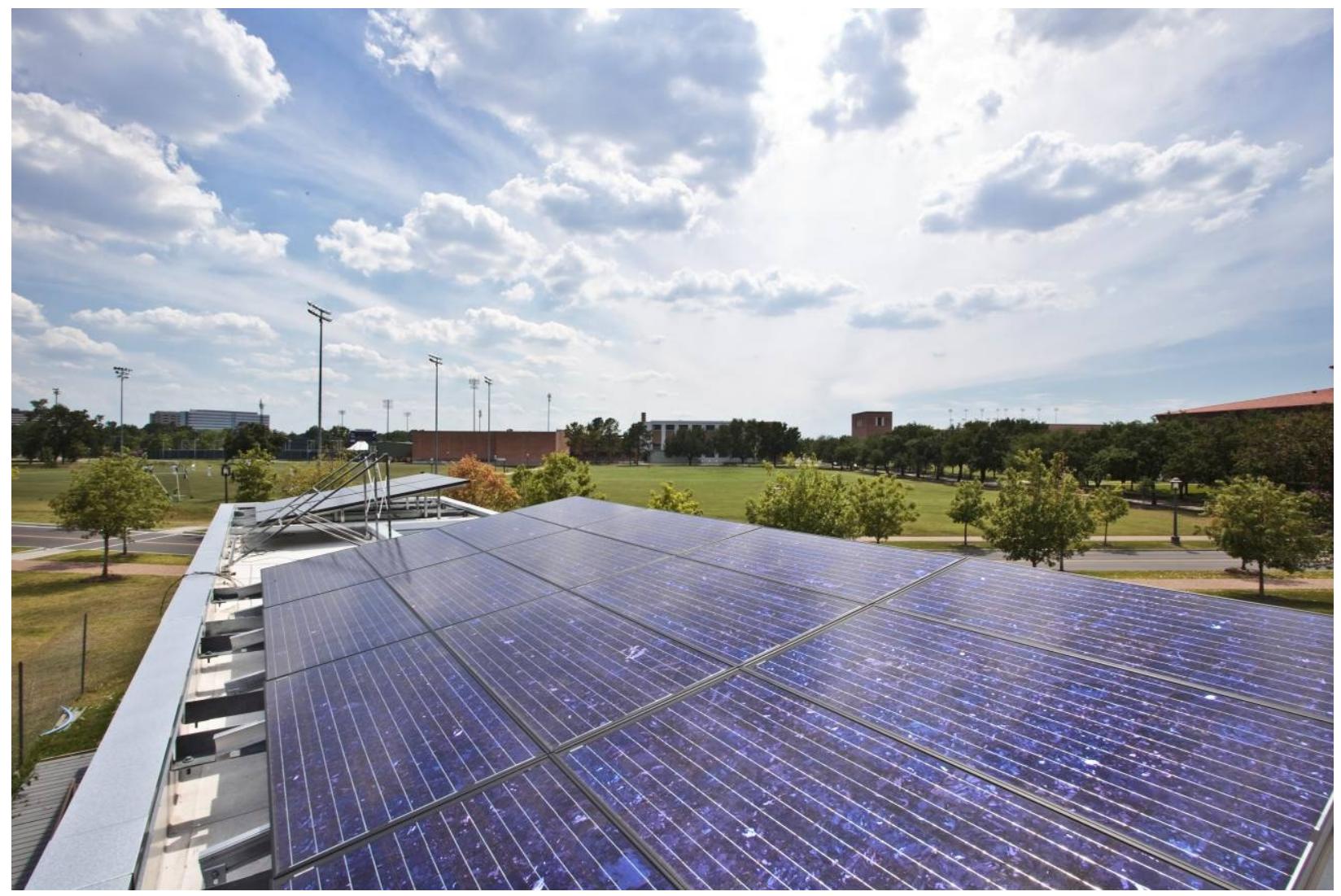

FIGURE 6

Photovoltaic arrays in the orientation at Rice University. The solar hot water Racking system sits between the two arrays. The orientation With tubes and panels angled to the back of the house is opposite the configuration on the National Mall (photo by Eric Hester C)

Solar Hot Water System

Hot water is generated through solar energy using an Apricus 30 Tube evacuated collector mounted on the roof ${ }^{\mathrm{xv}}$. Heat is conducted from the inner surface of each glass tube to a smalldiameter, sealed copper heat pipe via a fin. The copper heat pipes contain a freeze-resistant 
working fluid. One end of the copper tubes are inserted into a heat exchanger (header) through which the domestic water supply is cycled. The assembly of this system is shown in Figure 7 in the ZeRow's final location at PRH, backed by the Houston skyline. Hot water is stored in a wellinsulated tank, rated at a loss of only $1{ }^{\circ} \mathrm{C}$ per hour. Temperature measurements at the tank and header provide sensing for an Apricus control system to determine when it is beneficial to run the recirculation pump. For extended periods of low insolation, a point-of-use Stiebel Eltron Tempra 12 inline resistive heater provides additional heating of water after it leaves the tank, on its way to the kitchen, bathroom or laundry closet.

\section{Heating, Ventilation and Air Conditioning}

The ZeRow House is heated and cooled through a mini-split ductless system mounted at the two ends of the house in the bedroom and living room. Though not common in the U.S., this HVAC system is very efficient ( $30 \%$ more efficient than conventional split systems) and eliminates

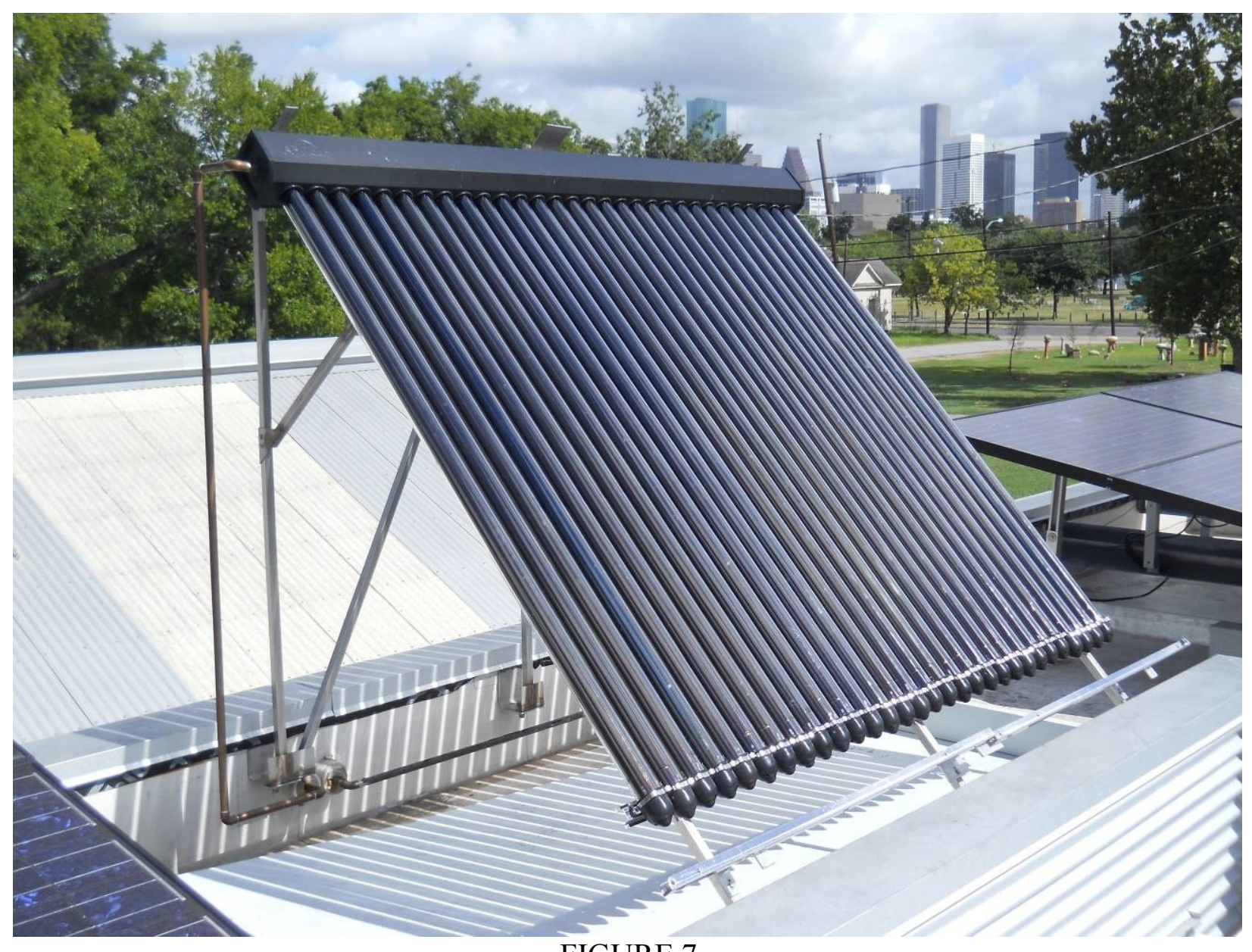

FIGURE 7

Apricus 30 Tube SOlar hot WATER ASSEMBLy ON THE ROOF WITH THE EDGES OF THE TWO SOLAR ARRAYS SHOWn On EITHER SIDE. (PHOto by Roque SANChez)

ductwork. The SEER (Seasonal Energy Efficiency Ratio) is about 18, compared to 12 for the average U.S. air conditioning unit. 
An Energy Recovery Ventilator exchanges stale air from the interior with fresh air from the exterior, while exchanging heat and humidity between the airstreams to reduce the additional demands on the HVAC.

Ceiling fans in the bedroom and living room supplement the air-conditioning in the summer and provide stand-alone comfort on moderate fall and spring days when the humidity is lower. By reversing the direction of the blades in the winter, the fans can help re-circulate warm air. It is estimated that $10 \%$ of the energy used for heating could be saved with the use of ceiling fans.

\section{Solar Decathlon}

Following an inaugural Decathlon in 2002, the U.S. Department of Energy has hosted the Solar Decathlon every two years since 2005. In this decathlon, 20 teams from the U. S. and abroad each build solar-powered houses, which are displayed on the National Mall in D.C. at the end of the competition. While on the National Mall, these houses are judged on a wide range of contests. Although these contests change slightly from decathlon to decathlon, they generally look at each house's marketability, livability, and buildability. Overall, the goals of the decathlon are to raise public awareness of residential solar systems and encourage their use.

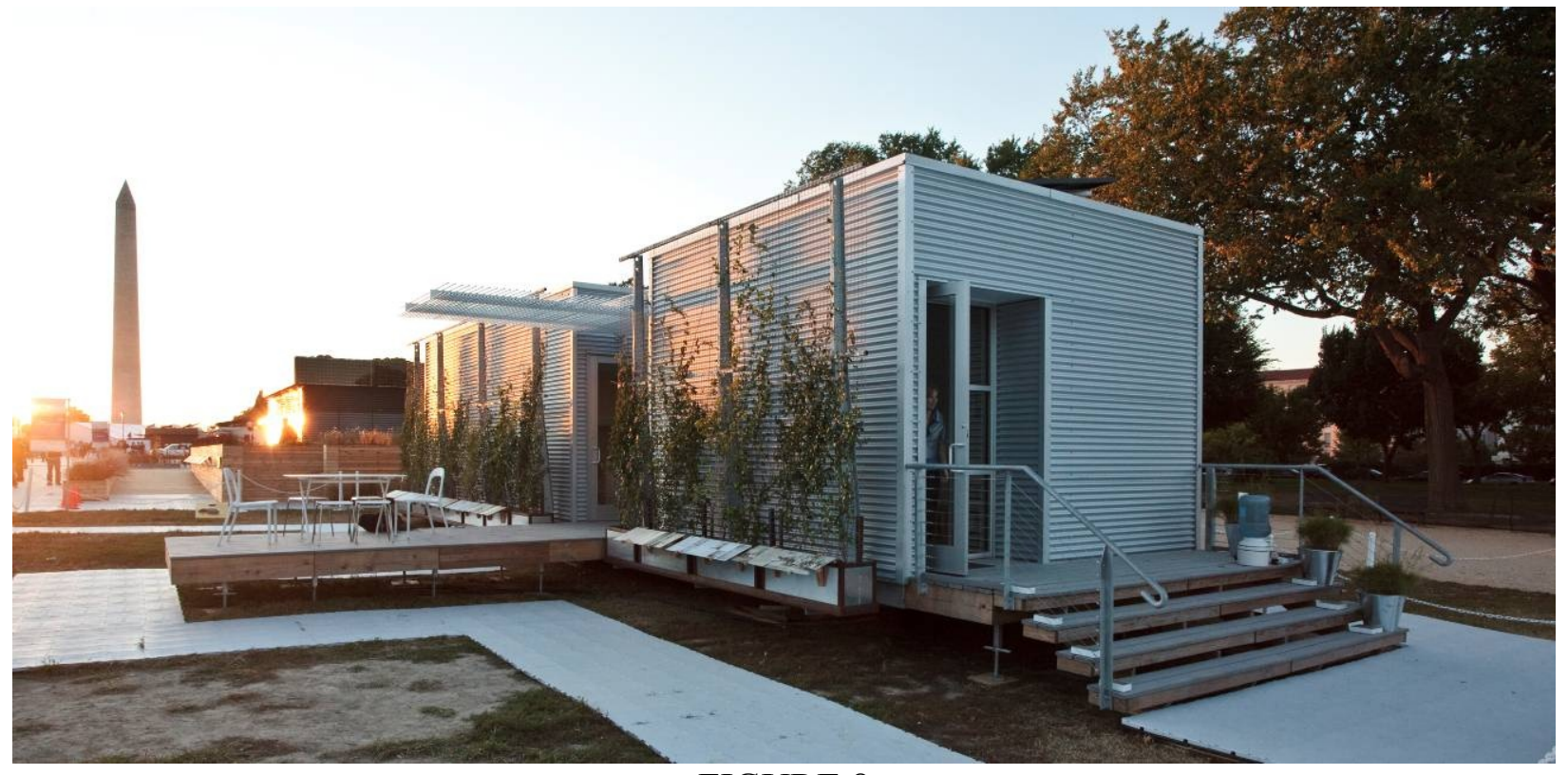

FIGURE 8

ZeRow House on the National Mall in Washington, D.C. (Photo by Eric Hester C)

\section{Jury Panels}

Five of the ten contests of the Solar Decathlon, including architecture, market viability, communications, engineering, and lighting design, are judged by juries. These juries are comprised of prominent individuals who have substantial knowledge and expertise in one of the five subjective contests. The ZeRow House placed very well in a number of the contests while maintaining the lowest budget of all teams. The ZeRow House was awarded second place in both architecture and market viability. Jury members praised the house for its clean-lined envelope, 
shaded porch, green wall, and off-the-shelf components. The team was awarded fifth place in communications for clean and informative signage and user-friendly website. These accomplishments, along with the performance in the other five quantitative categories, contributed to the ZeRow House's overall achievement: eighth place.

The high marks in both architecture and market viability confirmed the idea that innovative design and sustainability could be paired with affordability. The architecture jury noted that the house "really excelled--it was restrained but impressive, with a very sincere focus on economics." The market viability jury commented that the ZeRow House team "delivered a project that sets a remarkable standard for affordability while still meeting the challenge of netzero energy in a hot, humid climate." The ZeRow House was the only house of twenty to fall into the Solar Decathlon's most affordable cost bracket. Beyond jury recognition, many public visitors appreciated the modesty of materials and the use of readily-available products, illustrating how sustainability may be achieved by homeowners with more limited budgets.

\section{Monitoring and Performance}

The energy balance for the ZeRow House over the duration of the Solar Decathlon competition is shown in Figure 9. While a net-zero balance was achieved at the end of the first week, poor weather conditions forced the team to skip several competitions at the end of the last week, including water boils, towel drying and eventually control the interior climate on the final day. Days 3, 5, 7 and 8 saw very low insolation due to heavy cloud cover and rain. Temperatures on days 7 and 8 were unseasonably cold, and humidity was very high. The ZeRow House, having the smallest solar array of the 20 houses, was particularly affected by poor weather in the shortterm. However, the focus on quality insulation and efficient HVAC systems meant that the ZeRow House experienced relatively small gradients in energy consumption compared to nearly every other house. 


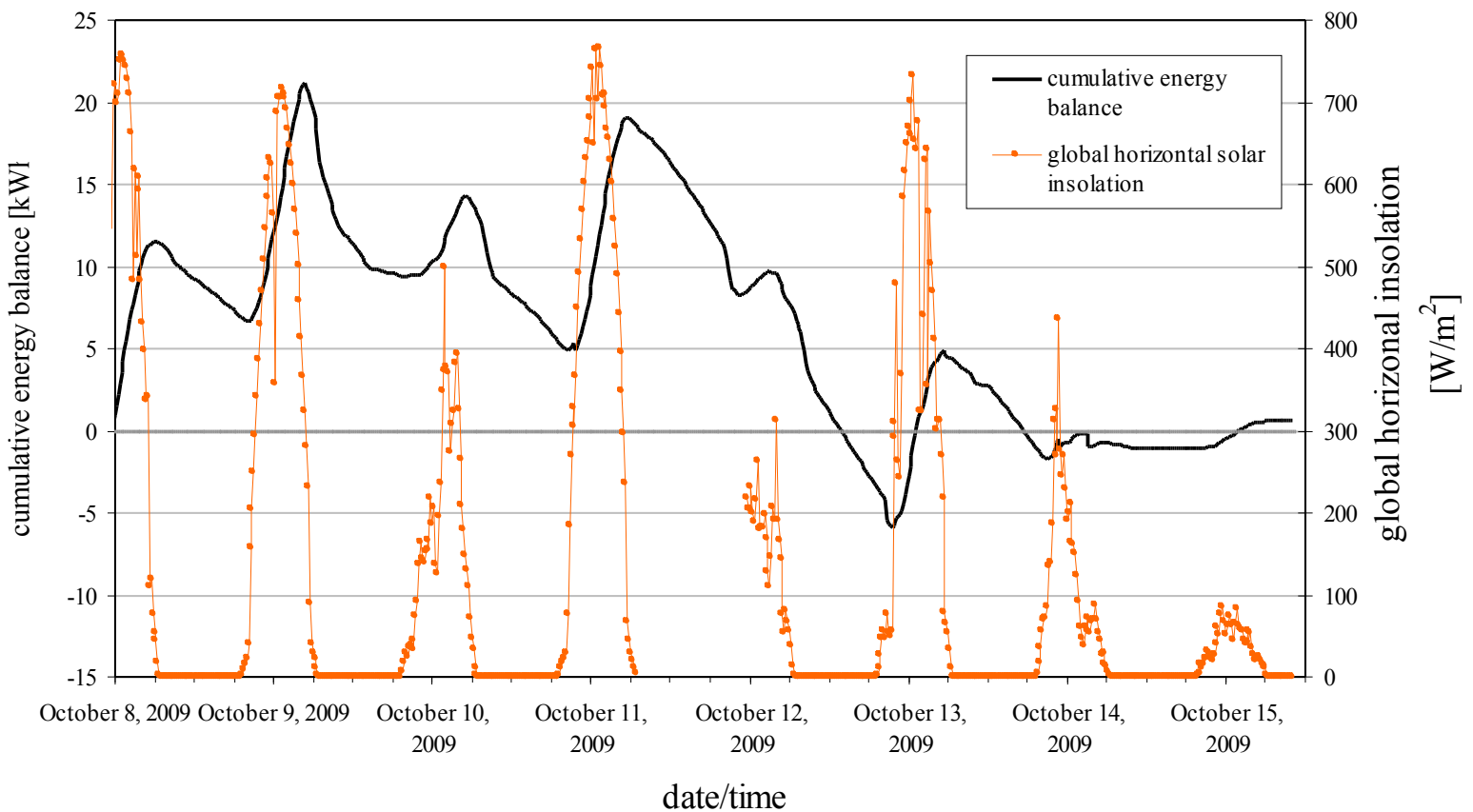

FIGURE 9

ZeRow House energy balance and associated global horizontal insolation on the National Mall during the Solar Decathlon, October 8 through October 15, 2009

\section{Public Awareness, Educational Outreach and Community Integration}

Throughout the duration of the project the ZeRow team was concerned with sharing this project with the wider community. This was achieved at various points throughout the decathlon, and extensive media coverage played a large role in achieving this goal. The ZeRow House was featured nationwide in prominent newspapers and on major television networks, which included the following: USA Today, Houston Chronicle, Popular Mechanics, Washington Post, AIArchitect, Reuters, Los Angeles Times, NBC "Today Show," CNN, and CBS News. These media placements highlighted the main goals of the ZeRow House and shared the team's story to build an affordable solar-powered home. In addition, these placements gave the team the opportunity to teach the public about residential solar-power systems.

Three ZeRow House tours and open houses in Houston, held at various times prior to the house's completion, in addition to the 10-day exhibition on the National Mall, gave the team the opportunity to share the house with the community on a more personal level. It is estimated that up to 30,000 people toured the ZeRow House between these venues. The goal of these events was to show the public that with certain adjustments to their home they could save money. These earnings are achieved by making a house more energy efficient-using LED lighting or Energy Star appliances-and changing living habits,-using a clothes line to dry clothes or opening windows and doors for cooling-which will lower electricity bills. Homeowners that use solarpower systems could possibly even produce more energy than they use, which would result in them receiving money from their electric provider.

While on the National Mall, the team also tried to include the D.C. community. One way in which they did this was to invite a graffiti artist Cory Stowers of Words Beats \& Life Inc., a 501c non-profit in Washington, DC, to paint the water shed, which contained the ZeRow 
House's above-ground water storage tank used throughout the competition. This simple act enhanced the beauty of the ZeRow House and expressed a commitment to include the community in the project.

The integration of the ZeRow House, both architecturally and socially, into the PRH community was possible because of the long-time collaboration between RBW and PRH. From the beginning, in frequent meetings with stakeholders, the team took the needs and wants of PRH into consideration. Throughout the project, the Rice Solar Decathlon Team remained in close contact with PRH staff and board so that the ZeRow House could adapt to PRH needs when possible. Four types of typical PRH occupants can be accommodated: a single or couple, a single mother with infant or an artist-in-residence.

\section{Implementation at Project Row Houses}

When the ZeRow team began its project, it did so with a conscious effort to meet the needs of members of the community while including them in the discussion on solar energy. This decision not only informed the design and price of the ZeRow House but also gave the house a future: the house would become a lasting part of Houston's Third Ward community. Its installation at Project Row Houses (PRH), the overarching goal of the project, began on November 3, 2009 when the ZeRow House was crane-lifted for the fourth and final time onto its permanent foundations at 2306 Stuart Street in Houston. This step marked the end of the Solar Decathlon and the beginning of the house's life at PRH.

During the spring and summer of 2010, physical installation continued. Students of the Rice Building Workshop installed all the transported components, such as the decks and stairs, sunshade, and the solar-power systems Mechanical, electrical, data, and plumbing systems were connected into the city grid by master tradesmen working with apprentices and students. Sidewalks and landscaping were installed to comply with City of Houston building requirements. The numerous city inspections were conducted and, eventually, all requirements were met. In a parallel effort, PRH hosted a fundraiser in which Rice students and faculty offered tours of the house in exchange for donations to pay to run a sewer line to the house. Finally, in August, 2010, all construction was completed, and the first resident moved in. Steffani Jemison, a Core Fellow of the Glassell School of the Museum of Fine Arts, Houston, and an Artist-In-Residence at Project Row Houses is living in the house for its inaugural year. When asked for her observations on the house design (and its departure from more traditional row houses) Jemison replied, "Cities enable you to experience layers of history as they are being made. Communities are never static - architecture in particular expresses the time in which it was made and I think the house will be a very inspiring place to live and work." 
Ms. Jemison is assisting the team by monitoring her energy related lifestyle. In particular she is tracking laundry usage and climate control settings. Monitoring and data collection continues using the Enphase Enlighten system. Array production for during a cloudy, rainy six days is shown in Figure 10. Production for a nearly cloudless five days followed by one partly cloudy day is shown in Figure 11. 


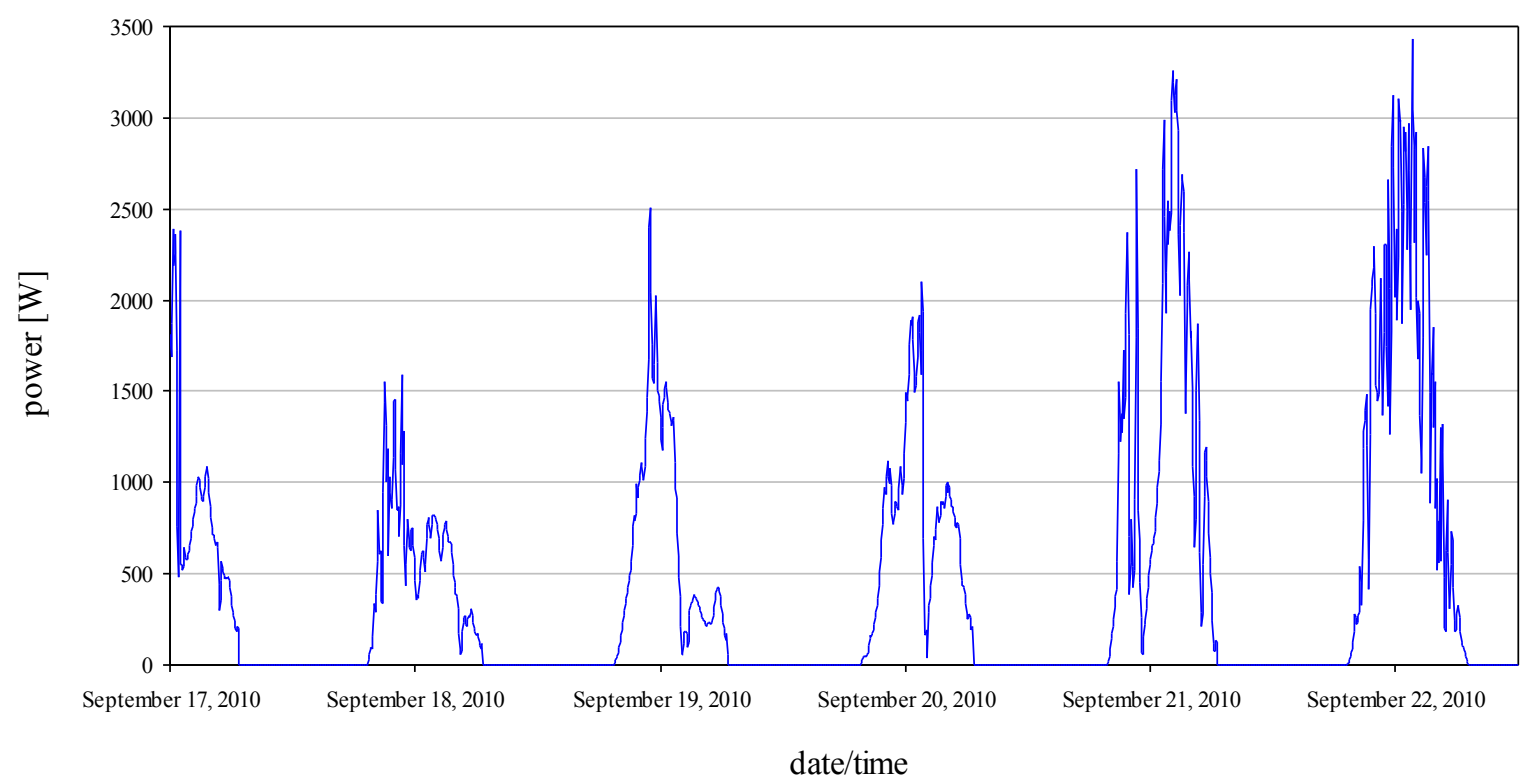

FIGURE 10

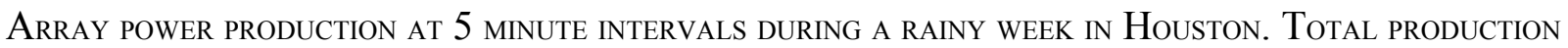
FOR SIX DAYS FROM 9/17/2010 THROUGH 9/22/2010 WAS $65.2 \mathrm{KWH}$

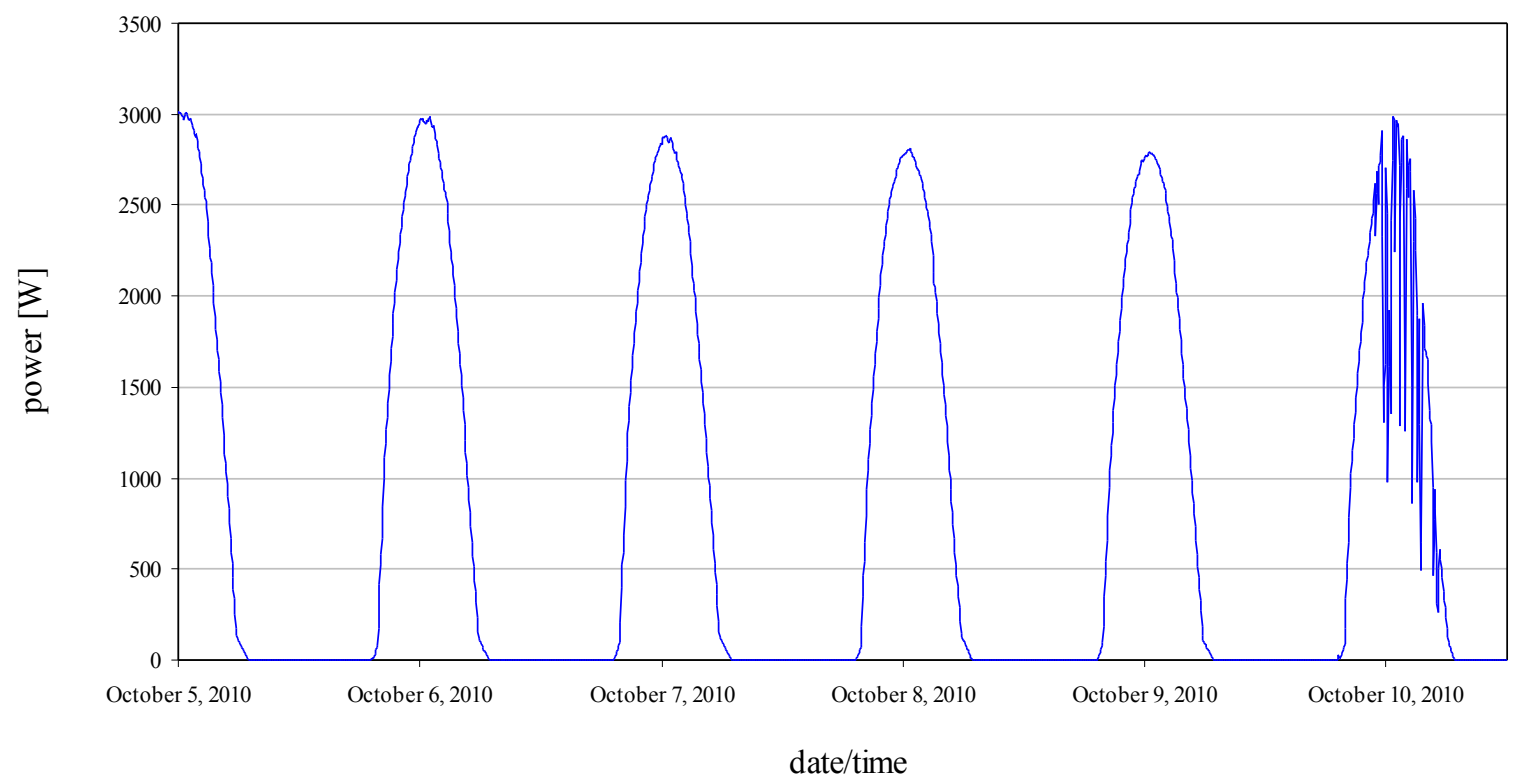

FIGURE 11

ARRAY POWER PRODUCTION AT 5 MINUTE INTERVALS DURING A SUNNY FIVE DAYS AND ONE PARTLY CLOUDY AFTERNOON IN Houston. TOTAL PRODUCTION FOR SIX DAYS FROM 10/5/2010 THROUGH 10/10/2010 WAS $117.1 \mathrm{KWH}$

On October 2, 2010 the ZeRow was open to the public and toured by approximately 70 people during the Houston Solar Tour, hosted by the American Solar Energy Society ${ }^{\mathrm{xvi}}$. 


\section{Cost Analysis}

The project cost as built were:

\begin{tabular}{ll} 
house construction & $\$ 77,612$ \\
technical systems (PV and solar hot water) & $\$ 16,795$ \\
installation at Project Row Houses & $\$ 14,000$ \\
\hline total construction cost & $\$ 108,407$
\end{tabular}

This amount includes certain features required by the constraints of the Solar Decathlon, such as the steel chassis, that would not necessarily be required for an on-site construction. It excludes certain costs for labor that was carried out by students, and some materials that were donated by suppliers. Many of the technical systems were donated or provided at significantly reduced cost.

To calculate the actual cost anticipated for reproducing the ZeRow House, an analysis according to Means Residential Detailed Costs: Contractor's Pricing Guide ${ }^{\text {xvii }}$ yields a cost for contractor-built construction, including technical systems, of $\$ 122,200$. Adding the cost of installation on-site of $\$ 14,000$, and deducting the cost of the steel chassis of $\$ 15,000$, the total cost, without land, would be $\$ 123,200$, or $\$ 237.00$ /square foot. For comparison, the construction cost for a two bedroom, 600 square-foot apartment recently built by PRH was about $\$ 100,000$. With some subsidy for the solar systems, and accounting for the cost of land, the cost could fall within the definition of 'affordable,' that is, a family of two or three with $80 \%$ median income in the Houston area could afford the mortgage payments or the rent.

The sponsors of the Solar Decathlon retained a cost consultant to prepare an estimate for each project, for comparative purposes. This estimate for the ZeRow House came to \$208,335 for contractor construction, with technical systems and minus the chassis and footings required for transport. This is about $\$ 400 /$ square foot, an extremely high figure given that very few custom building materials were used. Even at this estimate, the ZeRow House was still the least expensive 2009 Solar Decathlon house, by between a factor of 2 and 4 .

Further analysis points to the current technologies that are or are not yet competitive with market purchased electricity. Most notably, electricity produced from photovoltaic arrays is still approximately double the cost of grid purchased electricity, at least at current rates. However, solar hot water generation is very efficient, with a payback time on the order of a few years for typical consumption.

\section{ACKNOWLedgment}

The ZeRow House could not have been completed without the support of countless organizations, corporations, and individuals. A grant from the U.S. Department of Energy provided the primary support for the project. The Rice Design Alliance, Rice Faculty Initiatives Grant, the Rice University Shell Center for Sustainability, Boyer Brothers Construction, and Dr. Francisco Loya also provided generous support. Special thanks is given to the Houston Area Plumbing Joint Apprenticeship Committee and International Brotherhood of Electrical Workers Houston Joint Apprenticeship Training Committee for the countless hours they volunteered to complete the plumbing and electrical needs of the ZeRow House. The ZeRow House also greatly benefited from support given by Rice University's Development Office and Public Relations Office. Their assistance helped raise the funds and awareness that made the ZeRow House a success. Thanks are also due to the countless individuals, contractors, corporations, and faculty who also volunteered their time, talents, and resources to make the project a reality. (Deans of the School of Architecture Lars Lerup, John Casbarian, and Sarah Whiting, and Dean of 
Engineering Sally Keller-McNulty) Lastly, and most importantly, thanks are given to the students who initiated this project, saw it through its completion, and shared it with the community.

\section{REFERENCES}


${ }^{i}$ U.S. Energy Information Administration. Annual Energy Outlook 2009, with Projections to 2030. Form DOE/EIA-0383. 2009.

ii U.S. Energy Information Administration, Annual Electric Power Industry Report. Form EIA-861. 2009.

iii Ellerman, A. D. and Buchner, B. K., The European Union Emissions Trading Scheme: Origins, Allocation, and Early Results, Review of Environmental Economics and Policy 2007 1(1):66-87.

iv National Renewable Energy Laboratory. U.S. Department of Energy Solar Decathlon 2009.

${ }^{v}$ Roque T. Sanchez, The Design and Performance of Building-Scale Distributed Energy Generation in Houston, Texas, MS Thesis, Rice University, May 2010.

${ }^{v i}$ National Renewable Energy Laboratory. “U.S. Department of Energy Solar Decathlon 2009”, Request for Proposals. 2007.

vii www.projectrowhouses.org

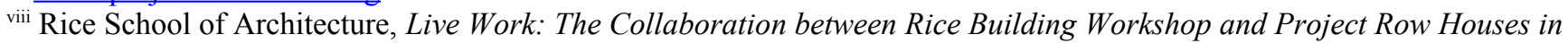
Houston, Texas. Architecture at Rice 42, Houston, 2006.

ix Brown, D. and Williams, W., Row: Trajectories Through the Shotgun House. Architecture at Rice 40, Houston, Rice University School of Architecture, 2004.

${ }^{x}$ Bell, B., Good Deeds, Good Design: Community Service Through Architecture. New York, Princeton Architectural Press, 2004.

${ }^{x i}$ Architecture for Humanity, Design Like You Give a Damn: Architectural Responses to Humanitarian Crises. New York, Metropolis Books, 2006.

xii Prouve, J., Prefabrication, Structures and Elements. New York, Praeger, 1971.

xiii Kieran, S. and Timberlake, J., Refabricating Architecture: How Manufacturing Methodologies Are Poised to Transform Building Construction. New York, McGraw-Hill, 2003.

${ }^{\text {xiv }}$ Rice School of Architecture, Core Houses: Projects by the Rice Building Workshop. Lulu Press, 2010.

${ }^{x v}$ Apricus, www.apricus.com

${ }^{x v i}$ http://www.houstonsolartour.com

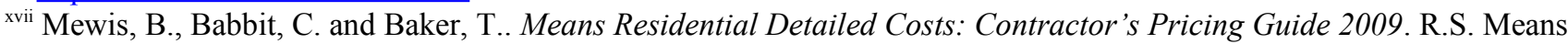
Company. 2008. 